\title{
Development of OASYS-2: a system for the analysis of serial measurement of peak expiratory flow in workers with suspected occupational asthma
}

\author{
P F G Gannon, D T Newton, J Belcher, C F A Pantin, P S Burge
}

\begin{abstract}
Background - Serial peak expiratory flow (PEF) measurement is usually the most appropriate first step in the confirmation of occupational asthma. Visual assessment of the plotted record is more sensitive and specific than statistical methods so far reported. The use of visual analysis is limited by lack of widespread expertise in the methods. A computer assisted diagnostic aid (OASYS-2) has been developed which is based on a scoring system developed from visual analysis. This removes the requirement for an experienced interpreter and should lead to the more widespread use of the technique.
\end{abstract}

Methods - PEF records were collected from workers attending an occupational lung disease clinic for investigation of suspected occupational asthma and from workers participating in a study of respiratory symptoms in a postal sorting office. PEF records were divided into two development sets and two gold standard sets. The latter consisted of records from workers in which a final diagnosis had been reached by a method other than PEF recording. An experienced observer scored individual work and rest periods for the two development set PEF records; linear discriminant analysis was used to compare measurements taken from development set 1 records with visual scores. Two equations were produced which allowed prediction of scores for individual work or rest periods. The development set 2 was used to determine how these scores should be used to produce a whole record score. The first gold standard set was used to determine the whole record score which best separated those with and without occupational asthma. The second set determined the sensitivity and specificity of the chosen score.

Results - Two hundred and sixty eight PEF records were collected from 169 workers and divided into two development sets ( 81 and 60 records) and two gold standard sets (60 and 67 records). Linear discriminant analysis produced equations predicting the score for work periods incorporating five indices of PEF change and one for rest periods using seven indices. These equations correctly predicted the score for development set 1 work and rest periods on $61 \%$ of occasions $(\kappa=0 \cdot 47)$. The whole record score for development set 2 records, after weighting for definite or definitely no occupational effect, correlated with the visual score (correlation coefficient $0 \cdot 86$ ). Comparison with gold standard set 1 identified a cut off which proved to have a sensitivity of $75 \%$ and a specificity of $94 \%$ for an independent diagnosis of occupational asthma when applied to gold standard set 2 .

Conclusions - These results suggest that the sensitivity and specificity of analysing PEF records for occupational asthma using OASYS-2 approaches that of visual analysis, but it should be absolutely reproducible. The performance of OASYS2 is more specific and approaches the sensitivity of other statistical methods of analysis. The evaluation of a large number of PEF records from workers exposed to different sensitising agents suggests that these results should be robust and should be repeatable in clinical practice.

(Thorax 1996;51:484-489)

Keywords: occupational asthma, peak expiratory flow, diagnosis.

The diagnosis of occupational asthma can usually be suspected from the history. Confirmation of the diagnosis is important as the consequences for the worker, both in terms of health and livelihood, are considerable. ${ }^{1}$ The most applicable currently available test is the serial measurement of peak expiratory flow (PEF). ${ }^{23}$ However, self measurement of PEF is not without its problems - for example, there is a variable time delay between exposure and asthma, many meters are non-linear, ${ }^{4}$ and workers vary in their ability to perform unsupervised recordings and often show a learning effect at the start of a record. The meters may be incorrectly read and falsification of records is possible. Individuals with occupational asthma also develop asthma related to non-specific triggers, particularly exercise and respiratory infection. These changes, and the changes due to treatment, need to be differentiated from those due to work exposure.

The original study by Burge et al divided the PEF record into work and rest periods and each period was visually classified as showing work-related change or not. ${ }^{23} \mathrm{~A}$ whole record subjective score was then produced as a per- 
Table 1 Summary of the results of previous evaluations of visual and statistical analysis

\begin{tabular}{|c|c|c|c|c|c|}
\hline \multirow[t]{2}{*}{ Patient group exposure } & \multicolumn{2}{|c|}{ Visual analysis } & \multicolumn{2}{|c|}{ Statistical analysis } & \multirow[t]{2}{*}{ Author } \\
\hline & $\begin{array}{l}\text { Sensitivity } \\
(\%)\end{array}$ & $\begin{array}{l}\text { Specificity } \\
(\%)\end{array}$ & $\begin{array}{l}\text { Sensitivity } \\
(\%)\end{array}$ & $\begin{array}{l}\text { Specificity } \\
(\%)\end{array}$ & \\
\hline Isocyanate/colophony & $42-77$ & 100 & $50-93$ & $40-67$ & Burge et $a l^{23}$ \\
\hline Western red cedar & 86 & 89 & - & - & Cote $e t a l^{8}$ \\
\hline Western red cedar & 87 & 90 & $66-93$ & $80-90$ & Cote $e t a l^{9}$ \\
\hline Mixed agents & 81 & 74 & 44-76 & $14-78$ & Perrin et $a l^{10}$ \\
\hline Mixed agents & - & - & 72 & 53 & Liss et al ${ }^{11}$ \\
\hline
\end{tabular}

centage of work and rest periods showing workrelated changes. A cut off of $75 \%$ produced a specificity of $100 \%$ with a variable sensitivity ranging from $42 \%$ to $77 \%$ when compared with a final diagnosis based on re-exposure at work. Further work has shown this method to be reasonably reproducible between experienced interpreters. ${ }^{5}$ A number of other authors have ascertained the sensitivity and specificity of visual interpretation of different PEF plot formats on worker groups exposed to a single agent and other groups exposed to a variety of agents. A summary of the results is shown in table 1 .

Visual inspection of plotted PEF records has, on the whole, been found to be more sensitive and specific than statistical analysis. A summary of the results of other statistical analyses is shown in table 1 . The problems with statistical analysis arise because improvement away from work may be progressive over several days resulting in some work days having higher PEF readings than rest days (fig 1 ).

We describe the development and evaluation of a computer-based decision aid (OASYS-2) for use with PEF records. The aims were to develop a computer-assisted diagnostic aid for the identification of occupational asthma from serial PEF records plotted as daily maximum, mean, and minimum values, and to evaluate

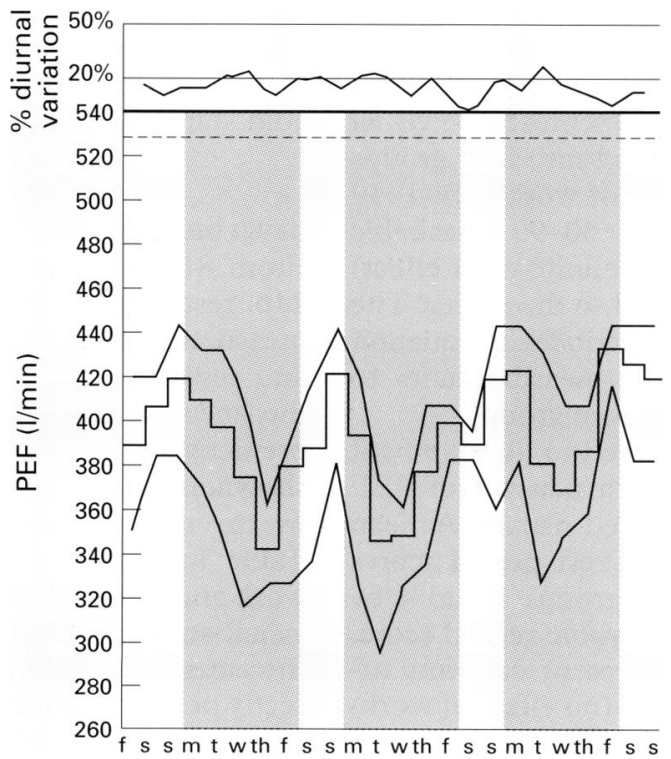

Figure 1 Two hourly serial PEF records performed on days at and away from work. The maximum, mean, and minimum is plotted for each day. The mean is the mean of all the readings performed on that day. Days involving any period at work are shaded. Diurnal variation as percentage predicted (maximum PEF-minimum PEF/ predicted PEF) and number of PEF readings per day are also shown. the developed diagnostic aid to determine its sensitivity and specificity when applied to a wide range of PEF records taken by workers from different industries with and without occupational asthma.

\section{Methods}

PEF records used in the study were collected as previously described. ${ }^{23}$ Workers were asked to measure PEF two hourly from waking to bed time, recording the best of three blows. If the highest two readings differed by more than $20 \mathrm{l} / \mathrm{min}$, then more readings were required. The minimum criterion required for a record to be included in this study was PEF readings over two work and two rest periods, with at least four readings per day. Records containing PEF patterns which made the plot visually uninterpretable were excluded; these included falls in PEF associated with respiratory tract infection and gradual improvements or deteriorations across the whole record. PEF records were collected sequentially from workers attending an occupational lung disease clinic with suspected occupational asthma and from a cross sectional survey of respiratory symptoms in post office sorting workers. Four sets of PEF records were used: two development sets and two gold standard sets - the latter from workers on whom a final diagnosis had been made using methods unrelated to serial PEF measurements. These non-PEF methods included specific bronchial provocation testing, a clear history of asthmatic symptoms related to work exposure which improved away from work, supplemented with either significant levels of specific IgE to a relevant occupational allergen or a fourfold change in non-specific bronchial responsiveness between periods at and away from work. We also included workers in whom symptoms had been completely abolished by removal from exposure to the causative agent. Gold standard negative records were supplemented by asymptomatic workers who had participated in the cross sectional survey of respiratory symptoms in the post office, and workers who had a final diagnosis of occupational asthma but were now relocated away from exposure to the causative agent.

The mean PEF value for each work "day" (starting with the first reading at work and continuing to the last reading before work the next day) was calculated and plotted with the maximum and minimum PEF for this period in the manner shown in fig 1 . Diurnal variation for each "day" expressed as the percentage predicted and the number of readings per day were also included on the plot. Fixed scale plots $(1 \mathrm{~cm}=20 \mathrm{l} / \mathrm{min})$ of the PEF records in development set 1 were visually scored from 0 (no evidence of work-related effect) to 100 (definite work-related effect) for each consecutive period of work or rest "days". Fifty possible measurements, qualitatively felt to best describe change between consecutive work/rest periods, were entered into a linear discriminant analysis. ${ }^{6}$ Measurements from work and rest periods were analysed separately. Linear discriminant analysis determines which meas- 
Table 2 Summary of development set 1, development set 2, gold standard 1 and gold standard 2 PEF sets

\begin{tabular}{|c|c|c|c|c|}
\hline & $\begin{array}{l}\text { Development } \\
\text { set } 1\end{array}$ & $\begin{array}{l}\text { Development } \\
\text { set } 2\end{array}$ & $\begin{array}{l}\text { Gold } \\
\text { standard } 1\end{array}$ & $\begin{array}{l}\text { Gold } \\
\text { stamdard } 2\end{array}$ \\
\hline $\begin{array}{l}\text { Number of records } \\
\text { Isocyanate exposure } \\
\text { Oil mist exposure } \\
\text { Metal exposure (Cr, Ni, Co) } \\
\text { Flour exposure } \\
\text { Colophony exposure } \\
\text { Epoxy resin exposure } \\
\text { Glutaraldehyde exposure } \\
\text { Wood dust exposure } \\
\text { Post office dust exposure } \\
\text { Other exposures } \\
\text { Mean record duration (days) } \\
\text { Mean readings per day } \\
\text { Mean number work periods } \\
\text { Mean number rest periods }\end{array}$ & $\begin{array}{l}81 \\
17 \% \\
15 \% \\
10 \% \\
4 \% \\
7 \% \\
4 \% \\
0 \\
0 \\
0 \\
43 \% \\
32 \\
8 \cdot 1 \\
4 \cdot 5 \\
4 \cdot 5\end{array}$ & $\begin{array}{r}60 \\
21 \% \\
6 \% \\
10 \% \\
6 \% \\
6 \% \\
4 \% \\
0 \\
6 \% \\
0 \\
41 \% \\
37 \\
7 \cdot 8 \\
5 \cdot 1 \\
5 \cdot 2 \\
\end{array}$ & $\begin{array}{l}60 \\
8 \% \\
0 \\
8 \% \\
0 \\
5 \% \\
0 \\
7 \% \\
0 \\
38 \% \\
34 \% \\
26 \\
7 \cdot 5 \\
3 \cdot 5 \\
3 \cdot 5\end{array}$ & $\begin{array}{l}67 \\
3 \% \\
9 \% \\
0 \\
4 \% \\
7 \% \\
9 \% \\
0 \\
0 \\
51 \% \\
17 \% \\
26 \\
7 \cdot 6 \\
3 \cdot 8 \\
3 \cdot 7\end{array}$ \\
\hline $\begin{array}{l}\text { Whole record opinion } \\
\text { (visual interpretation): } \\
\text { Occupational asthma } \\
\text { Equivocal } \\
\text { Asthma (not work-related) } \\
\text { Normal/COPD }\end{array}$ & $\begin{array}{l}29(36 \%) \\
11(14 \%) \\
26(32 \%) \\
15(18 \%)\end{array}$ & $\begin{array}{r}23(38 \%) \\
6(10 \%) \\
15(25 \%) \\
16(27 \%)\end{array}$ & $\begin{array}{l}- \\
- \\
- \\
-\end{array}$ & $\begin{array}{l}- \\
- \\
-\end{array}$ \\
\hline $\begin{array}{l}\text { Independent diagnosis } \\
\text { Occupational asthma } \\
\text { No occupational asthma }\end{array}$ & $\overline{-}$ & - & $\begin{array}{l}27(45 \%) \\
33(55 \%)\end{array}$ & $\begin{array}{l}32(48 \%) \\
35(52 \%)\end{array}$ \\
\hline $\begin{array}{l}\text { Method of independent diagnosis } \\
\text { Specific challenge } \\
\text { Bronchial hyperreactivity } \\
\text { Positive IgE RAST } \\
\text { Asymptomatic post office worker } \\
\text { Other }\end{array}$ & $\begin{array}{l}- \\
\overline{-} \\
\overline{-} \\
-\end{array}$ & $\begin{array}{l}- \\
- \\
- \\
-\end{array}$ & $\begin{aligned} 14 & (23 \%) \\
8 & (13 \%) \\
4 & (7 \%) \\
24 & (40 \%) \\
10 & (17 \%)\end{aligned}$ & $\begin{aligned} 17 & (25 \%) \\
5 & (8 \%) \\
9 & (13 \%) \\
34 & (51 \%) \\
2 & (3 \%)\end{aligned}$ \\
\hline
\end{tabular}

Table 3 Comparison of visual scores with scores predicted by OASYS-2 for development set 1. Work periods (rest periods in parentheses)

\begin{tabular}{|c|c|c|c|c|c|c|c|c|c|c|}
\hline \multirow[t]{2}{*}{ Group assigned by expert } & \multirow{2}{*}{\multicolumn{2}{|c|}{$\begin{array}{l}\text { Number of } \\
\text { complexes }\end{array}$}} & \multicolumn{8}{|c|}{$O A S Y S-2$ group score (\%) } \\
\hline & & & 1 & & 2 & & 3 & & 4 & \\
\hline Group 1 (no occupational asthma) & 84 & (104) & 61 & (66) & 21 & (35) & 2 & (3) & 0 & (0) \\
\hline $\begin{array}{l}\text { Group } 2 \text { (possible occupational } \\
\text { asthma) }\end{array}$ & 51 & (43) & 9 & (3) & 26 & (33) & 16 & (6) & 0 & (1) \\
\hline $\begin{array}{l}\text { Group } 3 \text { (probable occupational } \\
\text { asthma) }\end{array}$ & 33 & (45) & 0 & (5) & 12 & (15) & 18 & (21) & 3 & (4) \\
\hline Group 4 (occupational asthma) & 55 & $(54)$ & 0 & & 8 & (9) & 17 & (14) & 30 & (30) \\
\hline
\end{tabular}

urements are most predictive of the visual score and works most efficiently when there are a small number of categorical scores. The visual scores were therefore divided into four groups as follows: $1=0$ (no effect of work), $2=1-49$ (possible work effect), 3=50-99 (probable work effect), and $4=100$ (definite work effect) based on what they signified to the scorer. The discriminant analysis also produces an equation to apply to the identified measurements to predict membership of a score group.

The equations were applied to development set 2 to evaluate them on a new set of PEF records which had been scored visually. A mean of the individual work and rest period scores was used, weighting score groups 1 and 4 by a factor of 2 to produce a whole record score. This was because the degree of certainty attached to a visual score of 1 (no effect of work) or 4 (definite work-related effect) was greater than that applied to a score of 2 (possible work effect) or 3 (probable work effect).

The equations and the technique for calculating a whole records score (together termed OASYS-2) were applied to gold standard set 1 to determine the sensitivity and specificity of different whole record cut off scores for the presence or absence of a work-related effect as determined by the gold standard result.

The cut off point determined on gold standard set 1 was then applied to whole record scores calculated for gold standard set 2 to determine a final sensitivity and specificity for the presence of a work-related effect as determined by the gold standard result.

\section{Results}

Details of the four PEF sets used to develop and evaluate OASYS-2 are summarised in table 2 ; a total of 268 records were used from 169 workers. In the case of workers from whom more than one PEF record was used in the study, only the PEF records of four individuals appeared in both development and gold standard sets; however, these were completely different records separated by long periods of time with different exposures. The mean duration of each PEF record was 26-37 days depending on the set, the mean number of work periods was $3 \cdot 5-5 \cdot 1$ and rest periods $3 \cdot 5-5 \cdot 2$ per record, and the mean number of $\mathrm{PEF}$ readings per day in each group was $7 \cdot 5-8 \cdot 1$, consistent with the instruction to perform two hourly PEF measurements whilst awake. All groups contained PEF records from workers exposed to a wide variety of agents with a mixture of workers taking no medication, inhaled bronchodilators alone, and bronchodilators with inhaled steroids. Development set 1 was the largest with all types of PEF record being represented including the most difficult type - namely, those which were equivocal for the presence of a work-related effect (14\%) and $50 \%$ were not thought to show a workrelated effect. A similar distribution of PEF records was seen in development set $2(10 \%$ equivocal, $52 \%$ no work-related effect). Both gold standard sets contained a relatively even distribution of records from workers with occupational asthma ( $45 \%$ and $48 \%)$. The methods used for independent diagnosis in the gold standard sets are shown in table 2 .

\section{DEVELOPMENT SET 1}

From 81 PEF records 223 work periods and 246 rest periods were visually scored. Five measurements of PEF change for work periods and seven for rest periods were identified by the linear discriminant analysis as being most predictive of the visual score group and are shown in figs 2 and 3 . The equations produced by the analysis are shown in the Appendix. Table 3 compares the score group attached to work and rest periods in development set 1 by visual analysis with that predicted by applying the equations; $73 \%$ of work periods were correctly predicted by the equation as group 1 (no effect of work) when compared with that given by visual analysis, $51 \%$ were correctly predicted as group 2 (possible work-related effect), 55\% were correctly predicted as group 3 (probable work-related effect), and $55 \%$ were correctly predicted as group 4 (definite work-related effect); two (4\%) work periods were incorrectly predicted by more than one group but no work 


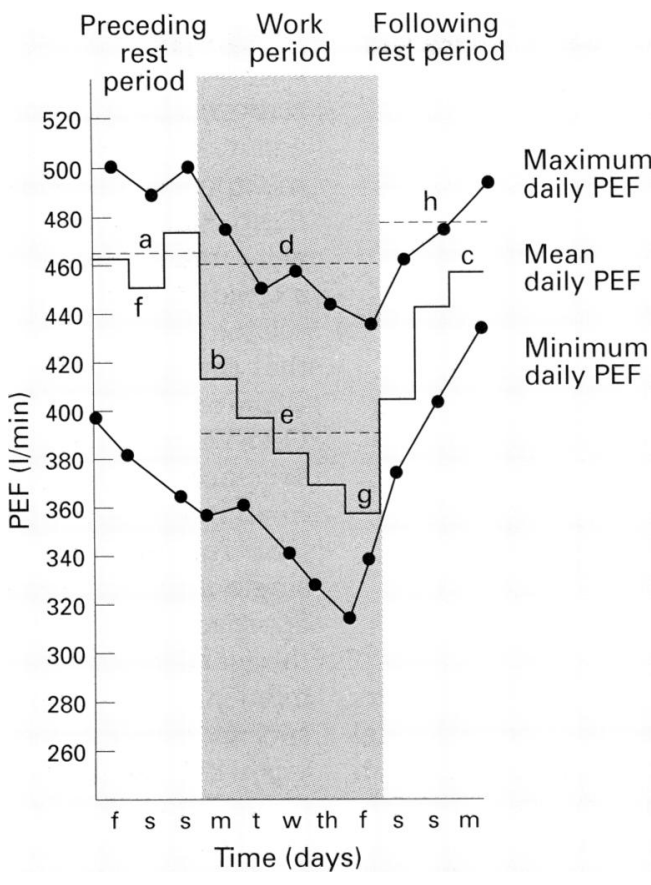

Figure 2 PEF indices determined to be predictive of work-related change for work periods. $a-b=$ mean of daily $P E F$ means preceding (rest period) - maximum of daily $P E F$ means (work period); $c-d=$ maximum of daily $P E F$ means following (rest period) - mean of daily PEF maximums (work period); $a-e=$ mean of daily PEF means preceding (rest period) - mean of daily PEF means (work period); $f-g=$ minimum of daily PEF means preceding (rest period) - minimum of daily PEF means (work period); $h-d=$ mean of daily PEF maximums following (rest period) - mean of daily PEF maximums (work period).

periods were incorrectly predicted by more than two groups. Eighteen $(7 \%)$ rest periods were incorrectly predicted by more than one group and one rest period $(0.4 \%)$ was incorrectly classified by more than two groups. The equation for rest periods appeared to produce more significant errors in score prediction than for work periods. Overall, the percentage assigned to the correct score group by both equations was $61 \%$. A moderate strength of agreement was suggested by a $\kappa$ value of 0.47 for both work and rest periods. Considering

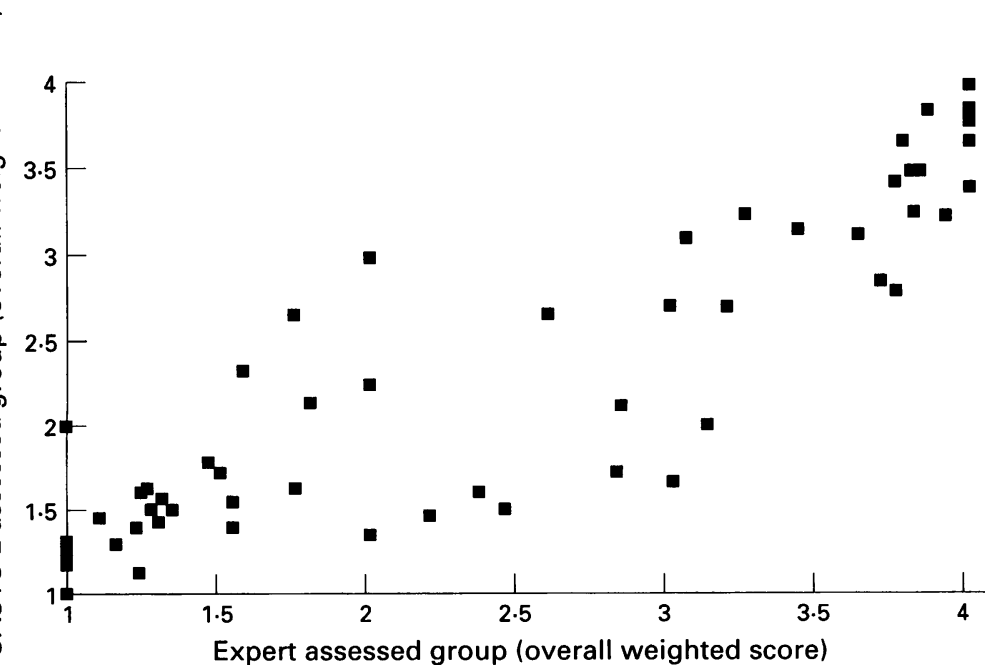

Figure 4 Comparison of visual weighted whole record scores with OASYS-2 scores for the development set 2.

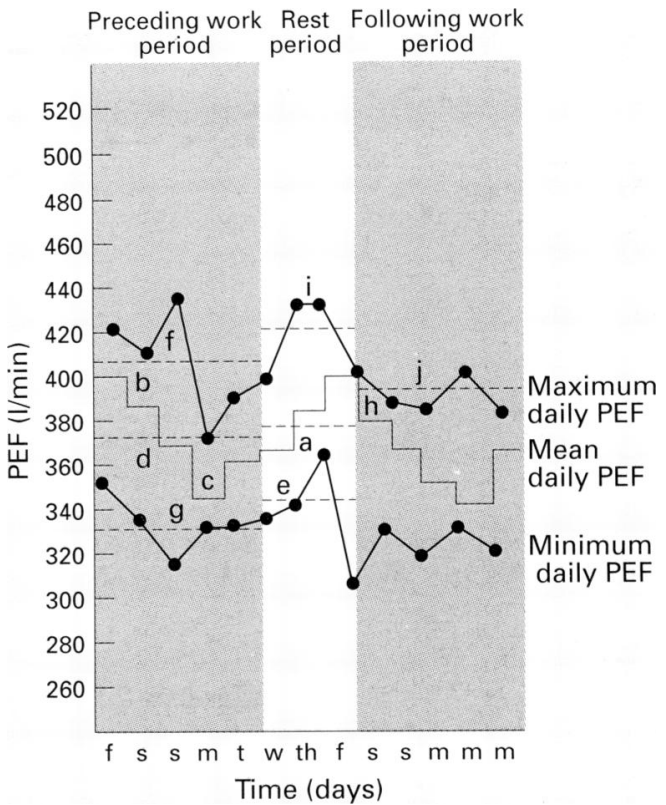

Figure 3 PEF indices determined to be predictive of work-related change for rest periods. $a-b=$ mean of daily $P E F$ means (rest period) - maximum of daily PEF means preceding (work period); $a-c=$ mean of daily PEF means (rest period) - minimum of daily PEF means preceding (work period); $a-d=$ mean of daily PEF mean (rest period) - mean of daily PEF means preceding (work period); $e-f=$ mean of daily PEF minimums (rest period) - mean of daily PEF maximums preceding (work period); $a-g=$ mean of daily PEF means (rest period) - mean of daily PEF minimums preceding (work period); $e-h=$ mean of daily PEF minimums (rest period) - maximum of daily PEF means following (work period); $i-j=$ mean of daily PEF maximums (rest period) - mean of daily PEF maximums following (work period).

any pattern in the prediction of an incorrect score, for work periods $21 \%$ of incorrect predictions were underestimates and $18 \%$ were overestimates, and for rest periods $19 \%$ were underestimates and $20 \%$ were overestimates.

\section{DEVELOPMENT SET 2}

The results of the comparison of weighted whole record scores produced by visual analysis and OASYS- 2 on the 60 test PEF records are shown in fig 4 which shows a qualitatively good association between the two methods of analysis (Pearson correlation coefficient $0 \cdot 86$ ).

GOLD STANDARD EVALUATION 1

The sensitivity and specificity for different cut off scores when applied to the scores produced by applying OASYS-2 to PEF records from gold standard set 1 are shown in fig 5 . A cut off predicted score of $\geq 2.51$ maximised sensitivity while maintaining a specificity of $100 \%$. At this cut off, no PEF record was predicted as having occupational asthma when this was not thought to be the final diagnosis; eight $(30 \%)$ PEF records were predicted as not having occupational asthma when this was thought to be the final diagnosis.

GOLD STANDARD EVALUATION 2

The cut off score of $\geq 2 \cdot 51$ was then applied to the OASYS-2 whole record scores from gold 


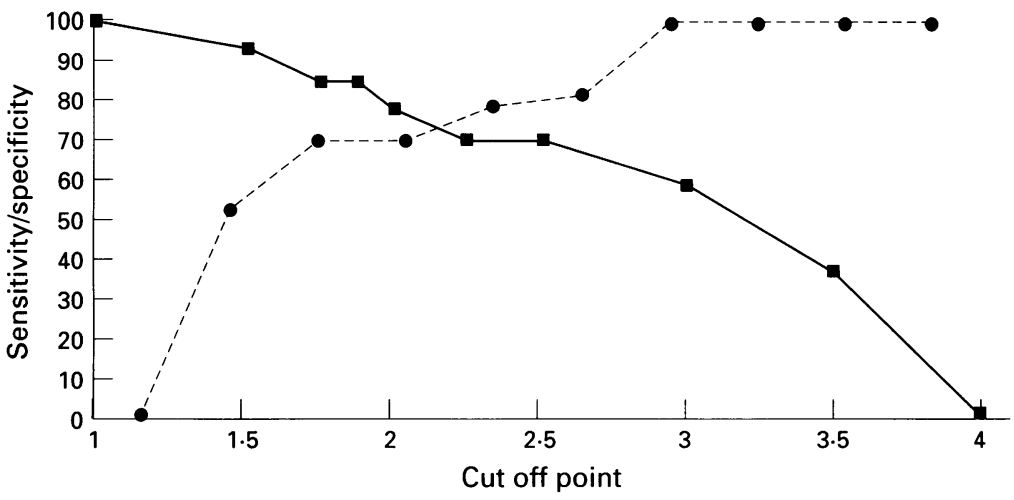

Figure 5 Curve used to determine the cut off point for whole record score which maximises sensitivity () while maintaining a specificity (○) of $100 \%$.

standard set 2 PEF records. Thirty two workers had an independent diagnosis of occupational asthma which OASYS-2 correctly predicted in 24 . The scores for the remainder were between 1.7 and $2 \cdot 38$. Thirty five records came from workers without occupational asthma, and OASYS- 2 scores exceeded 2.51 in two, both of which were from post office workers who gave no history of respiratory symptoms on the questionnaire. When these two PEF records were reviewed visually, one showed diurnal variation of up to $30 \%$ and a definite work-related effect (this record scored 3.29), and the other showed low diurnal variation and small improvements in PEF away from work (this record scored $2 \cdot 71$ ). Further investigation of these two individuals is indicated. These results show a sensitivity of $75 \%$ and a specificity of $94 \%$.

\section{Discussion}

Measurement of peak expiratory flow is available to nearly everybody, ${ }^{7}$ so its use in the initial assessment of occupational asthma is attractive both for the worker, who avoids being admitted to hospital for specific bronchial provocation testing, and for doctors as the costs and resources needed are far lower. If occupational asthma exists, it should be possible to demonstrate changes in PEF related to occupational exposure. Several authors have shown that subjective assessment of plotted records is superior to statistical analysis ${ }^{23910}$; the main limiting factor is the expertise needed for reproducible subjective analysis and the credibility of such a method. We have therefore tried to develop an assessment system which removes the subjectivity and non-reproducibility of expert assessed records. We have based the system, which we call OASYS-2 (because it is based on comparisons between two adjacent parts of the record), on the established method of serial PEF plotting ${ }^{23}$ which accentuates the differences between days at and those away from work. We have started by trying to reproduce the expert assessor and then used the resulting scores on PEF records with independently made diagnoses. The final evaluation is therefore independent of the subjective assessments and classifies individuals as either having or not having occupational asthma. This classification is probably too simplistic as some records were taken from workers who were only intermittently exposed, or who had been removed from direct exposure to the offending agent, where significant changes in PEF related to exposure may not necessarily be seen. Similarly, some records were from workers who were taking large doses of inhaled corticosteroids which would tend to mask any workrelated effect. ${ }^{23}$ The results presented suggest that the sensitivity and specificity of analysing PEF records for occupational asthma using OASYS-2 approach that of visual analysis. The specificity of $94 \%$ is greater than that obtained in all but the original work of Burge, in which PEF records from worker groups exposed to single agents were used. A sensitivity of $75 \%$ approaches that of other evaluations despite the fact that many of the workers were taking inhaled corticosteroids. OASYS- 2 is also more specific than other statistical methods of analysis with a similar sensitivity.

Factors which reduce the sensitivity and specificity of analysis by OASYS- 2 include the fact that it still relies on self-recorded PEF which suffers from problems of poor technique and sometimes, when compensation is an issue, frank falsification. Analysis is also critically dependent on knowing when a worker is exposed to a sensitising agent which is often difficult to assess, particularly when exposure is intermittent. This can sometimes be overcome by detailed record keeping by the worker but, because of the nature of many sensitisers, the worker may be unaware when exposure has occurred. The formulae used in the OASYS-2 system are based on the opinion of an experienced interpreter who will have good and bad days and, as such, will not be totally reproducible. It is therefore likely that the development set 1 contained incorrectly scored work or rest periods which may have detracted from the performance of the linear discriminant analysis. Another factor which may affect assessment of sensitivity and specificity is the quality of gold standards. False negative and false positive bronchial provocation tests can occur. A number of workers seen in our own unit have made dramatic recoveries when removed from exposure because of positive PEF recording despite having a negative specific bronchial challenge. It is notoriously hard to reproduce exactly the conditions at work when performing specific bronchial challenges, so negative results do not always equate with the absence of occupational asthma. Similarly, if challenges are not correctly controlled, false positive results may be produced by either irritant levels being achieved or a worker wishing to create a positive result. Another problem specific to this evaluation was the choice of gold standard negative records. We rarely perform bronchial provocation tests in workers who are unlikely to have occupational asthma. This leaves workers with PEF records and negative specific bronchial challenge in short supply. In this evaluation we therefore used records from asymptomatic post office workers in whom we had no reason to suspect occupational asthma. A number of these records showed no evidence of asthma, which may have served to assist 
OASYS-2 in correctly diagnosing them as not showing occupational asthma.

Despite these drawbacks of PEF recording, visual analysis and evaluation of the results produced by OASYS- 2 are encouraging. In clinical practice specificity is the most important index to evaluate because of the clinical and financial implications of a diagnosis of occupational asthma. ${ }^{1}$ A lower sensitivity is more easily tolerated as workers with false negative PEF values are likely to undergo further investigation if they have a good history of occupational asthma. The high specificity produced by OASYS- 2 when applied to a large number of PEF records from workers exposed to different sensitising agents suggests that this is a useful diagnostic aid which can be used in clinical practice by chest and occupational physicians. OASYS- 2 is currently being made available to these physicians for further evaluation in a more general clinical and occupational setting. The data are entered by the physicians (by hand or by downloading directly from electronic PEF meters) after the poorest quality records are excluded. A standard PEF plot (fig 1) is then produced, together with a report giving an overall score and conclusion. OASYS -2 is viewed as a prototype analysis system which may be improved in the future by the addition of refined analysis packages.

Occupational asthma remains a disease which is very substantially underdiagnosed ${ }^{1}$ and it is hoped that OASYS-2 will help to make the diagnostic process easier. The diagnosis of occupational asthma still leaves the problem of finding the specific cause, for which serial PEF measurements are not usually very helpful.

The authors would like to thank Drs Ahmed Al Shatti and Philip Bright from the Occupational Lung Disease Unit, Birmingham Heartlands Hospital for their help in collecting and entering PEF data, and Mr J Middleton from the School of Computing, Staffordshire University for computing advice. The work has been partly funded by grants from the Health and Safety Executive, the British Lung Foundation, the Medical Research Council, the Midland Thoracic Society, and the Chest, Heart and Stroke Association.

1 Gannon PFG, Weir DC, Robertson AS, Burge PS. Health, employment and financial outcomes in workers with oc-
cupational asthma. Br $\mathcal{F}$ Ind Med 1993;50:491-6.

2 Burge PS, O'Brien IM, Harries MG. Peak flow rates in the diagnosis of occupational asthma due to colophony. Thorax diagnosis of occupati

3 Burge PS, O'Brien IM, Harries MG. Peak flow rate records in the diagnosis of occupational asthma due to isocyanates. Thorax 1979;34:317-23.

4 Miller MR, Dickinson SA, Hitchings DJ. The accuracy of portable peak flow meters. Thorax 1992;47:904-9.

5 Venables KM, Burge PS, Davidson AG, Newman Taylor AJ. Peak flow rates in surveys: reproducibility of observers' reports. Thorax 1984;39:828-32.

6 SPSS PC +, SPSS Inc, 444 N. Michigan Avenue, Chicago, Illinois, USA.

7 Gannon PFG, Burge PS. The Shield scheme in the West Midlands, United Kingdom. Br f Ind Med 1993;50:791-6.

8 Cote J, Kennedy S, Chan-Yeung M. Sensitivity and specificity of $\mathrm{PC}_{20}$ and peak expiratory flow rate in cedar asthma. $\mathcal{F}$ Allergy Clin Immunol 1990;85:592-8.

9 Cote J, Kennedy S, Chan-Yeung M. Quantitative versus qualitative analysis of peak expiratory flow in occupational qualitative analysis of peak expirat

10 Perrin B, Lagier F, L'Archeveque J, Cartier A, Boulet LP, Cote J, et al. Occupational asthma: validity of monitoring of peak expiratory flow rates and non-allergic bronchial of peak expiratory flow rates and non-allergic bronchial
responsiveness as compared to specific inhalation chalresponsiveness as compared to

11 Liss GM, Tarlo SM. Peak expiratory flow rates in possible occupational asthma. Chest 1991;100:63-9.

\section{Appendix}

The equations presented in tables 4 and 5 allow a value to be calculated for each of the four score groups $(1=$ experienced interpreter score of $0,2=1-49,3=50-99$, and $4=100$ ). The group with the highest value is the group score predicted by the equation.

Table 4 Equation produced by discriminant analysis for predicting work period scores

\begin{tabular}{|c|c|c|c|c|c|}
\hline \multirow[t]{3}{*}{ PEF indices (measures on fig 2) } & & \multicolumn{4}{|c|}{ Group membership } \\
\hline & & \multicolumn{4}{|c|}{ Coefficients } \\
\hline & & 1 & 2 & 3 & 4 \\
\hline Mean mean PEF preceding rest period-maximum mean PEF work period (a-b) & Multiply by & $-0 \cdot 129$ & $-0 \cdot 128$ & $-0 \cdot 124$ & $-0 \cdot 178$ \\
\hline Maximum mean PEF following rest period - mean maximum PEF work period (c-d) & Multiply by & $\begin{array}{l}0 \cdot 034 \\
\text { plus }\end{array}$ & $\begin{array}{l}\text { plus } \\
0 \cdot 020 \\
\text { plus }\end{array}$ & $\begin{array}{l}\text { plus } \\
-0 \cdot 011 \\
\text { plus }\end{array}$ & $\begin{array}{l}\text { pius } \\
0 \cdot 032 \\
\text { plus }\end{array}$ \\
\hline Mean mean PEF preceding rest period-mean mean PEF work period (a-e) & Multiply by & $\begin{array}{l}0 \cdot 109 \\
\text { plus }\end{array}$ & $\begin{array}{l}0 \cdot 130 \\
\text { plus }\end{array}$ & $\begin{array}{l}0 \cdot 176 \\
\text { plus }\end{array}$ & $\begin{array}{l}0 \cdot 327 \\
\text { plus }\end{array}$ \\
\hline Minimum mean PEF preceding rest period - minimum mean PEF work period $(\mathrm{f}-\mathrm{g}$ ) & Multiply by & $\begin{array}{l}-0 \cdot 030 \\
\text { plus }\end{array}$ & $\begin{array}{l}0 \cdot 001 \\
\text { plus }\end{array}$ & $\begin{array}{l}0 \cdot 001 \\
\text { plus }\end{array}$ & $\begin{array}{l}-0.043 \\
\text { plus }\end{array}$ \\
\hline $\begin{array}{l}\text { Mean maximum PEF following rest period }- \text { mean maximum PEF work period }(h-d) \\
\text { Constant }\end{array}$ & Multiply by & $\begin{array}{l}-0 \cdot 038 \\
\text { plus } \\
-2 \cdot 073\end{array}$ & $\begin{array}{l}-0 \cdot 018 \\
\text { plus } \\
-2 \cdot 107\end{array}$ & $\begin{array}{l}0 \cdot 003 \\
\text { plus } \\
-2 \cdot 635\end{array}$ & $\begin{array}{l}0 \cdot 003 \\
\text { plus } \\
-4 \cdot 901\end{array}$ \\
\hline
\end{tabular}

Table 5 Equation produced by discriminant analysis for predicting rest period scores

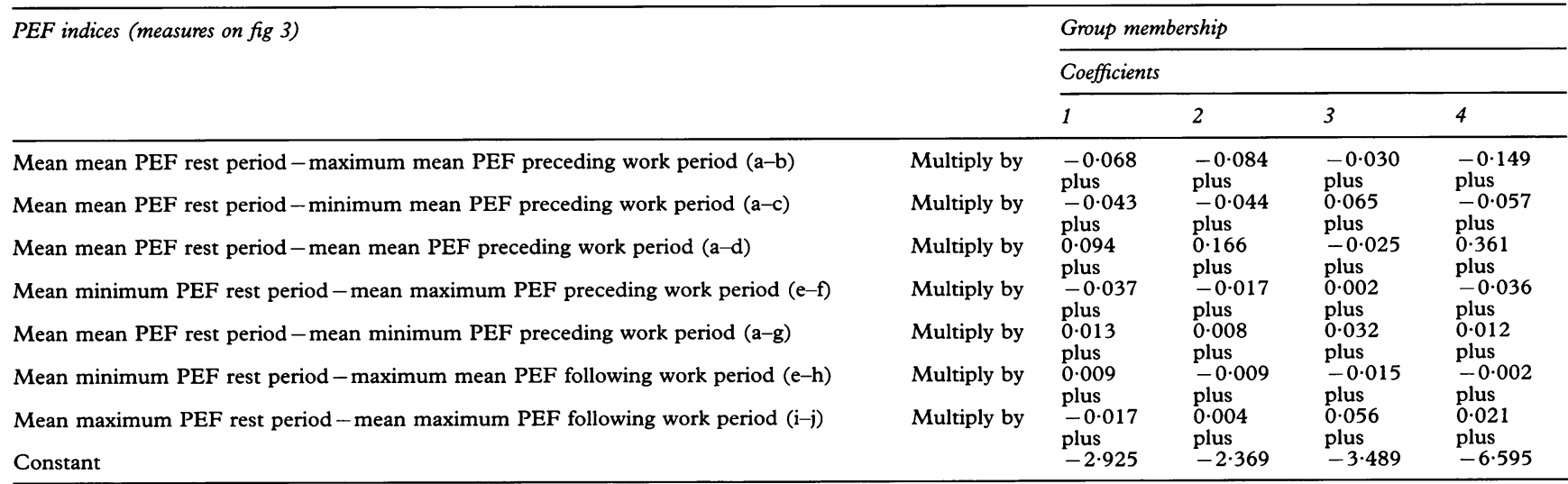

